\title{
Extruded collagen fibres and biphasic collagen sponge for rotator cuff tendon repair application: an ovine in vitro study
}

Zafar Ahmad

Neil Rushton

Orthopaedics, Orthopaedic Research Unit, University of Cambridge, Cambridge, UK

Corresponding author:

Zafar Ahmad

Orthopaedics, Orthopaedic Research Unit, University of Cambridge

Cambridge, UK

E-mail: ziaxj@hotmail.com

\section{Summary}

Introduction: High failure rates have been reported for rotator cuff repairs. Tendon grafts have been developed to augment these repairs. Two types of grafts are collagen sponge and collagen fibres. This study investigates the biocompatibility of a biphasic collagen sponge as a bone-tendon interposition device that may induce tendon regeneration, comparing its results to an established tendon graft.

Methods: Ovine tenocytes were exposed to either: (1) Control - a collagen fibre that has been shown to be conducive to tenocytes; (2) intervention - Chondromimetic, a novel biphasic tendon sponge, consisting of mineralized and unmineralized layers. The following parameters were measured over a three week period: cellular DNA, type I collagen, decorin, and glycosaminoglycan production.

Results: Tendon cells are able to adhere and multiply in the collagen sponge. The increase in cellular DNA, type I collagen, and glycosaminoglycan in the collagen sponge graft was similar to fibre graft over the study period.

Conclusion: Chondromimetic is biocompatible with ovine tendon cell growth.

Level of evidence: Illb.

KEY WORDS: tendon, augmentation graft, biphasic sponge.

\author{
Introduction
}

The tendon has a limited ability to regenerate following injury ${ }^{1}$. The rotator cuff tendon is prone to tears at its attachment to the tuberosity ${ }^{2,3}$. These tears may heal with scar tissue, which is weaker construct than native tendon. The aim of this study is to develop a method to regenerate normal tendon tissue after injury. Researchers are exploring a number of different solutions for promoting tendon healing, such as platelet rich plasma (PRP) 4,5 and mesenchymal stem cells ${ }^{6}$. Whilst these techniques are being explored in the clinical practice, laboratory research also continues into better tendon repair technique. Over the past few years, a number of grafts have shown the potential as augments for tendon repair, but these are still being investigated for clinical effectiveness ${ }^{7,8}$.

Recent advances in biomaterials have led to the development of a number of biosynthetic scaffolds for use in tendon repair ${ }^{8,9}$. These scaffolds provide an environment that supports regeneration, by allowing cellular infiltration due to the increased surface area to volume ratio and by mimicking the 3-dimensional environment of the extracellular matrix. One type of scaffold that has shown promise as an interpositional graft is the collagen sponge model ${ }^{10,11}$.

Chondromimetic (Tigenix, UK) is a novel biphasic collagen sponge that has been previously investigated by our group ${ }^{12,13}$. It is based on the collagen-glycoaminosglycan (GAG) technology, which has been under research for over three decades. Chondromimetic consists of an unmineralized bovine type I collagen/GAG (chondroitin-6-sulfate) layer attached to a bovine type I collagen/GAG "osseus" layer, premineralized with calcium phosphate in its brushite phase. Chondromimetic has been shown to be successful in osteochondral defects, and has a number of properties which may enable it to be used for tendon repair: (1) its biphasic nature makes it an ideal interpositional device for the bone-tendon repair, with the mineralised layer conducive to bone integration and the unmineralised layer suitable for tendon cell integration; (2) its porosity permits cellular infiltration; (3) it also has the ability to act as an activator of growth factor such as PRP ${ }^{14}$. To assess its potential we will compare it to another collagen graft that we have already explored with tendon cells.

Ligamimetic (Tigenix, UK) is a novel extruded collagen fibre graft, derived from bovine type I collagen ${ }^{15}$. It is a porous, resorbable tissue-regeneration scaffold that uniquely mimics the composition and structure of 
tendons. It has been developed to augment tendon repairs in cases of tendon tissue deficit either due to retraction or poor quality of tendon tissue. A number of in vitro and in vivo studies have found that the graft successfully integrates with the tendon ${ }^{15-17}$. It therefore provides an ideal comparison model for Chondromimetic.

Development of a new technology requires in vitro and in vivo experimentation, followed by human studies. We chose an ovine model to test the new graft due to its similarity in size and structure to the human tendon ${ }^{18}$. It has been used in numerous previous studies due to the ease of handling of animals, and reproducible results ${ }^{7}$. We have also had experience in working with this model.

This study investigates whether Chondromimetic is conducive to ovine tenocyte adhesion, cell growth, and cell activity in an in vitro setting. Our hypothesis is that Chondromimetic would demonstrate similar biocompatibility to Ligamimetic, as assessed with the following parameters: (1) cell proliferation, determined via DNA assay; (2) protein production; (3) glycoaminosglycan production.

\section{Methods}

\section{Overview}

Ovine tendon cells were harvested from the infraspinatus of three Welsh mountain sheep $(\mathrm{N}=3)$. These cells were then seeded in two separate groups (1) control group: Ligamimetic i.e. extruded collagen fibre graft; (2) Chondromimetic i.e. collagen sponge graft, and cultured for a three week period, with samples taken at weekly intervals. The sampled cells were measured for a number of factors: intracellular DNA quantity, decorin, fibronectin, type I collagen, and glycosaminoglycans. Type I collagen produced on the graft was quantified with Western blotting, and that released into the supernatant was determined with Dot blotting. The assessors undertaking the measurements were blinded to the groups.

\section{Tendon cell preparation}

The sheep work was done in accordance with the regulations set out in the Animals (Scientific Procedures) Act 1986. Ovine tendon cells were derived from the infraspinatus of the sheep. All tissue culture work was carried out under clean conditions of a tissue culture hood.

Tendon cells were prepared using $10 x$ concentration of antibiotic media, which was made using $100 \mathrm{ml}$ $10 \%$ foetal calf serum (FCS), $2 \mathrm{mM}$ glutamine, $5 \mathrm{ml}$ penicillin/streptomycin, $1 \mu \mathrm{l} / \mathrm{ml}$ amphotericin $\mathrm{B}, 10$ $\mathrm{ug} / \mathrm{ml}$ gentamycin added to $50 \mathrm{ml}$ of DMEM (high glucose). Each tendon sample was washed in this preparation for 1 hour. The tendon was then minced as finely as possible using a scalpel and added to 25 $\mathrm{ml} 0.2 \%$ collagenase (Sigma) solution (filtered sterilised) made in complete DMEM. The mixture was in- cubated in a shaker for $12 \mathrm{hrs}$. The cell suspension was then removed with a pipette and spun in a centrifuge at 1500 RPM for 5 minutes. The pellet was washed with fresh media to remove residual collagenase, and then re-suspended in fresh antibiotic media in a T175 flask. Cells were allowed to adhere, and then the media was changed every 2-3 days. Confluency of cells was generally reached at 2 weeks from the start of the procedure.

\section{Tissue culture media}

The composition of tissue culture media was as follows: $50 \mathrm{ml} \mathrm{FCS,} 5 \mathrm{ml}$ penicillin/streptomycin, $500 \mu \mathrm{l}$ of amphotericin $(1 \mu \mathrm{l} / \mathrm{ml})$, and 500ulof gentamicin (10 $\mu \mathrm{l} / \mathrm{ml}$ ) were added to a $500 \mathrm{ml}$ bottle of DMEM (with 2 $\mathrm{mM}$ of glutamine). The solution was stored at $4^{\circ} \mathrm{C}$ and warmed to $37^{\circ} \mathrm{C}$ before use.

\section{Trypsination and passage of cultured cells}

A T175 flask of cells was washed with $20 \mathrm{ml}$ HBSS $x 2$. Then $10 \mathrm{ml}$ Trypsin/EDTA was added and the mixture was placed in an incubator for up to $5 \mathrm{~min}$ utes. The cells were checked at regular intervals until they were rounded and had detached from the surface of the flask. Then $10 \mathrm{ml}$ of media prepared was added. The mixture was placed in a centrifuge at 1500 RPM for 5 minutes. The pellet was washed in fresh media to remove residual collagenase, and then resuspended in fresh media in a T175 flask. Cell measurements were made. Cells were passaged on a weekly basis. Cells at passage 3 were used for tendon cell culture.

\section{Cell culture}

A 96 well plate was hydrated with PBS and $0.500 \mathrm{~g}$ of either extruded collagen fibre or collagen sponge of equal weight were placed into each well. The wells were seeded with $10^{5}$ cells in $50 \mu \mathrm{l}$ DMEM, ensuring that the solution was deposited onto the scaffold. After seeding, the scaffolds were incubated for 5 hours, and then $150 \mu \mathrm{l}$ of cell media was added to each well. Each group of scaffolds was seeded in triplicates. Cells were cultivated in standard conditions: $37^{\circ} \mathrm{C}$, humidified $5 \% \mathrm{CO}_{2}, 95 \%$ air. The media was changed every third day, and aliquot stored for dot-blotting. Cells and culture plates were harvested by snap freezing at 7,14 , and 21 days. The scaffolds were replated at every media change.

\section{Cell proliferation assay}

The DNA from the cells on the scaffold was extracted by dissolving $0.250 \mathrm{~g}$ of the scaffold in $200 \mu \mathrm{l}$ papain digest buffer $(0.1 \mathrm{M}$ phosphate buffer $\mathrm{pH} 7,10 \mathrm{mM} \mathrm{L}$ cysteine, $2 \mathrm{mM}$ EDTA, $125 \mu \mathrm{l} / \mathrm{ml}$ papain), and incubating the solution overnight. Then $10 \mu \mathrm{l}$ of each DNA standard (Salmon testes) or sample was added to a 96 well plate and diluted in $90 \mu \mathrm{l}$ TNE buffer. Next $100 \mu \mathrm{l}$ Hoescht dye (blue fluorescent dyes for staining DNA) at concentration $0.2 \mu \mathrm{l} / \mathrm{ml}$ in TNE buffer was added to each well, which yielded a final dye concen- 
tration of $0.1 \mu \mathrm{l} / \mathrm{ml}$. The fluorescence was measured in a plate reader (360 nm Ex, $460 \mathrm{~nm} \mathrm{Em).}$

\section{Dot blotting}

The Dot blot was used to measure protein release in the supernatant of the cell. $100 \mu \mathrm{l}$ of each culture supernatants was transferred to a 96 well plate and diluted to $1: 1$ in PBS and filtered through the transfer membrane (Immobilon-P, Millipore Corp., Bedford, MA) using a dot-blotting apparatus (Bio-Dot Apparatus, Bio-Rad, UK).

\section{Western blotting}

Western blotting was used to measure decorin and type I collagen, produced in the matrix by the cells on the scaffold. These were selected as previous lab experiments have shown that the antibodies are compatible with sheep and have been shown to be important in tendon collagen fibrillogenesis ${ }^{19,20}$.

Running Buffer: Novex Tris-Glycine SDS Running Buffer Code LC2675-5.

Transfer Buffer: Novex Tris-Glycine transfer Buffer for Blotting (25x). Code LC 3675.

Sample Buffer: 4x concentrated solution. For $100 \mathrm{ml}$ : $24 \mathrm{ml} \mathrm{IM} \mathrm{HCl} \mathrm{pH} \mathrm{6.8,} 8 \mathrm{~g} \mathrm{SDS}$. Made to $60 \mathrm{ml}$ with water. Dissolved $40 \mathrm{mg}$ bromphenol blue and made to $100 \mathrm{ml}$ with glycerol.

$0.250 \mathrm{~g}$ of material was placed in $200 \mu \mathrm{l}$ of extraction buffer in an eppendorf overnight in a rotator at $4^{\circ} \mathrm{C}$. Next, $83 \mu \mathrm{l}$ of this mixture was added to $250 \mu \mathrm{l}$ of sample buffer solution. This was then heated to $60^{\circ} \mathrm{C}$ for 20-30 $\mathrm{min}$.

\section{Electrophoresis}

Western blot gels (Abcam, Cambridge, UK) were removed from packaging, and placed into gel assembly. The inner chamber was filled with running buffer to cover the wells, and the outer chamber. $25 \mu \mathrm{l}$ of each samples in duplicates was then added to each Western blot slot. A standard and $5 \mu$ of marker mixture [molecular weight marker (Amersham RPN 756) mixed with Invitrogens Magicmark] was also present in individual slots. The gels were then connected to a power supply (Biorad Power Pac 3000) for two hours at $100 \mathrm{~V}$.

\section{Transfer}

The apparatus was then disassembled, and placed in a transfer buffer unit using transfer membrane (Immobilon-P, Millipore Corp., Bedford, MA) and Whatman filter paper. Next, the chamber was filled with transfer buffer and connected to a power supply at $100 \mathrm{~mA}$ for two hours. After this, the Immobilon paper was processed according to the immunoprobing method.

\section{Immunoprobing}

The membranes were blocked for $1 \mathrm{hr}$ with PBS containing $0.1 \%$ Tween-20 and 5\% non-fat dry milk PBS (PBSTM), and then incubated overnight with primary antibodies: anti-collagen type I rabbit IgG (Rockland
600-4001-101-0.1) 1:1000 dilution, anti-fibronectin rabbit IgG (Rockland 600-401-117-0.5), anti-human tencin-C mouse IgG1 (IBL International-4F10TT), and anti-decorin goat IgG (Abcam). Membranes were then washed and incubated for 2 hrs with the appropriate species horseradish peroxidise-conjugated secondary antibody at 1:10000 dilution in PBSTM. Blots were visualised using the ECL Plus blotting system (GE Healthcare, UK) as per the manufacturer's instructions. Developed films were scanned using a GS-710 calibrated imaging densitometer and analyzed using Quantity One software (Bio-Rad, UK). The units of analysis were calculated as the absorbance units per unit $\mathrm{mm}^{2}$, which depends on the density of the blot.

\section{9-Dimethylmethylene Blue (DMMB) assay}

The DMMB assay was used to measure sulphated glycosaminoglycans (GAG). The assay is based on the ability of sulfated GAGs to bind the cationic dye 1,9-dimethylmethylene blue. This method was based on the technique used by Farndale et al. and modified by Graham Riley ${ }^{21}$ DMMB was prepared by mixing $16 \mathrm{mg} /$ litre DMMB (Sigma 341088), $40 \mathrm{mM}$ glycine (3.0 g/litre), $40 \mathrm{mM} \mathrm{NaCl}$ (2.34 g/litre), and adjusted to $\mathrm{pH} 3.0$ with concentrated hydrochloric acid. The assay was stored in the dark. A standard curve was created using shark chondroitin-4-sulphate C (Sigma C4384).

$40 \mu \mathrm{l}$ cell supernatant or standards to 96 well plate (using ELISA plates) followed by $250 \mu$ l of DMMB. This then placed into an ELISA reader, and read immediately at $540 \mathrm{~nm}$.

\section{Statistics}

Data were collected and analyzed with Excel (Microsoft, USA). All measurements from the samples taken from three sheep were amalgamated and analyzed by a $t$-test. Statistical significance was set at $p$ $<0.05$. A normal distribution for the data was assumed. The results were presented in bar graphs with error bars representing standard deviation.

\section{Results}

\section{DNA (Fig. 1)}

The findings show that tendon cells are able to adhere and multiply in the collagen sponge. The increase in DNA quantity in the collagen sponge graft was similar to fibre graft over the study period. Although this could be that due to the porous nature of the sponge, the collagen 3D structure, and glycosaminoglycan present, the expected DNA content would be higher in the collagen sponge, this was not seen.

\section{Western and Dot blots}

Cellular activity was demonstrated by measuring the production of type I collagen, decorin, and glycosaminoglycan. The Western blots showed that on 


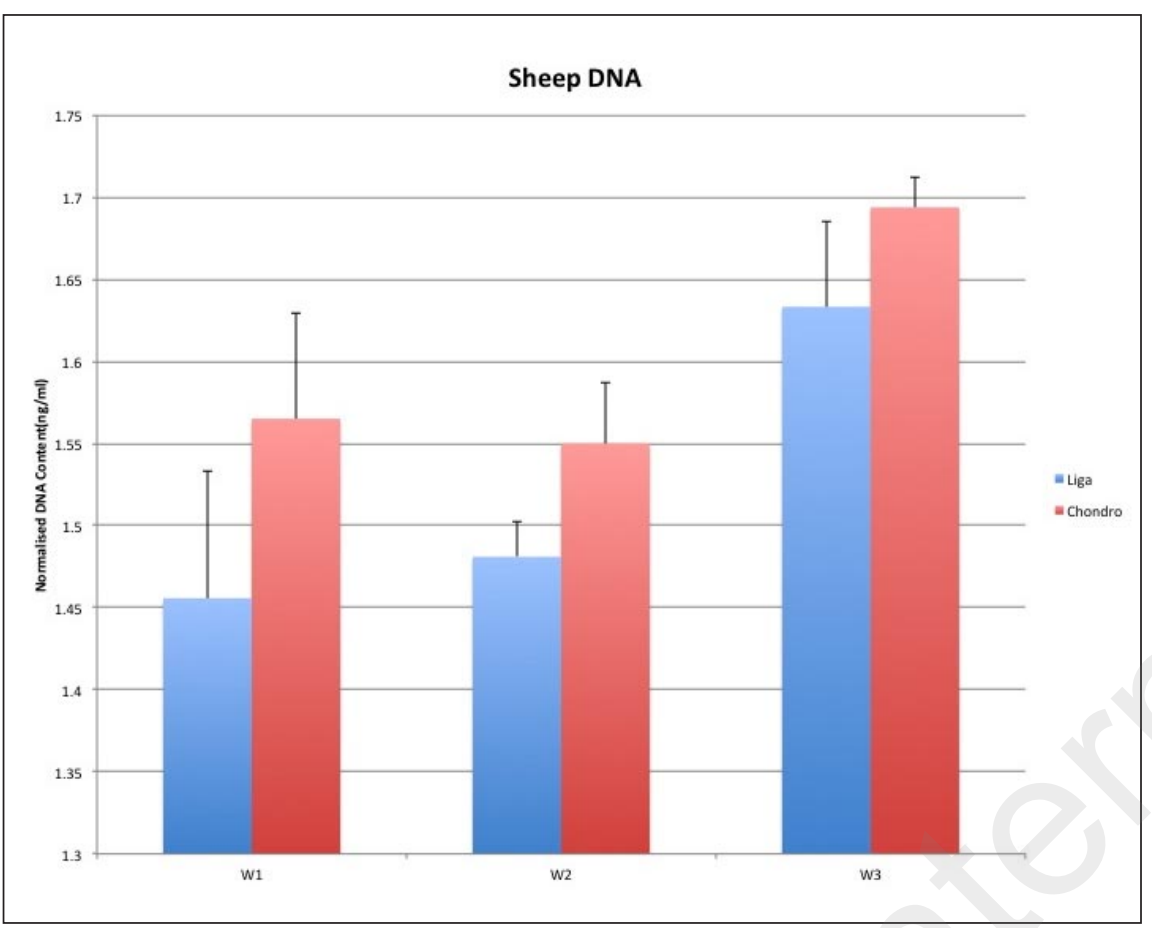

Figure 1. Tenocyte DNA measured over three weeks from both fibre and sponge.

collagen sponge, type I collagen production increased over the three weeks, but it was not statistically significantly different from that produced in the collagen fibres. The Dot blot showed a consistent rise in type I collagen produced on the supernatant, which was significantly greater than on the fibre graft. This could be because either the collagen produced on the fibre is more likely to be deposited on the graft, or that the tenocytes may be falling off the collagen sponge into the supernatant. Since the cellular DNA has been shown to increase over the three-week period on the graft, the former explanation might be more plausible.

The Western blot for decorin produced was significantly higher on the fibre graft as compared to the sponge. This suggests that protein production may not be all depositing on the graft or that the production of protein by the tenocytes may be influenced by the type of scaffold that the cells adhere to. A shortcoming of this study is that we did not dot blot for decorin, and therefore have not measured the amount of decorin released to the supernatant.

Decorin (Fig. 2)

Decorin production increased in both groups over the three-week period, but it was significantly greater on the collagen fibre graft than on the Chondromimetic graft $(p=0.047)$.

\section{Type I collagen (Fig. 3)}

Type I collagen produced on the two types of scaffold increased over the three-week period. There was no statistically significant difference between the groups $(p=0.42)$.

Type I collagen Dot blot (Fig. 4)

The Dot blot shows that significantly more type I collagen was released in the supernatant in Chondromimetic group than in Ligamimetic group ( $p=$ 0.048).

\section{GAG (Fig. 5)}

Glycoaminoglycans formation increased cumulatively at a similar rate in both groups $(p=0.90)$.

\section{Discussion}

The objectives of successful rotator cuff repair are to preserve range of movement and prevent long term complications of rotator cuff arthropathy, and thereby avoid interventions such as reverse total shoulder arthroplasty. Unfortunately rotator cuff repair can have a failure rate of up to $60 \%{ }^{22}$, and there is a need to develop new methods to improve rotator cuff healing. Tendon augmentation grafts have been developed to reinforce tendon repair and have shown preclinical success but not in human trials ${ }^{23,24}$. Ono et al. ${ }^{25}$ undertook a systematic review that stated tendon augmentation grafts can be beneficial to tendon repair, depending on the type of graft. For example small intestine mucosa graft was shown to be inferior, whereas human dermis was superior. This study had no randomized controlled trials present, making this 


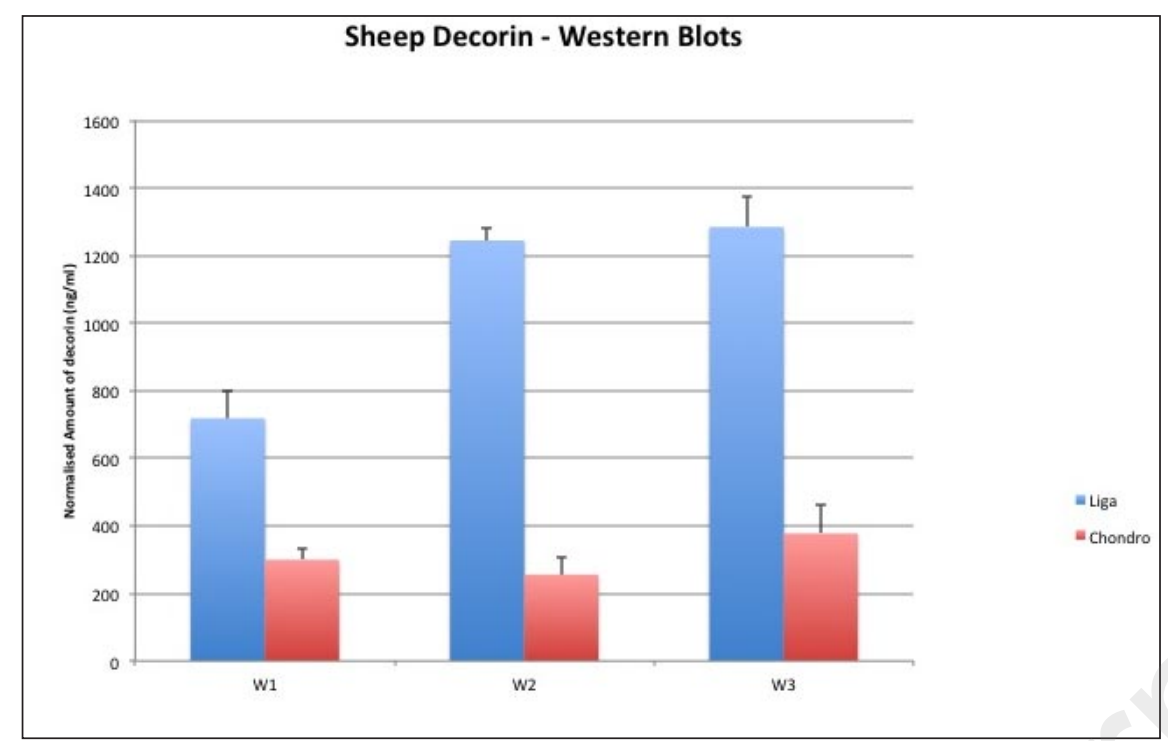

Figure 2. Decorin production over three weeks on graft.

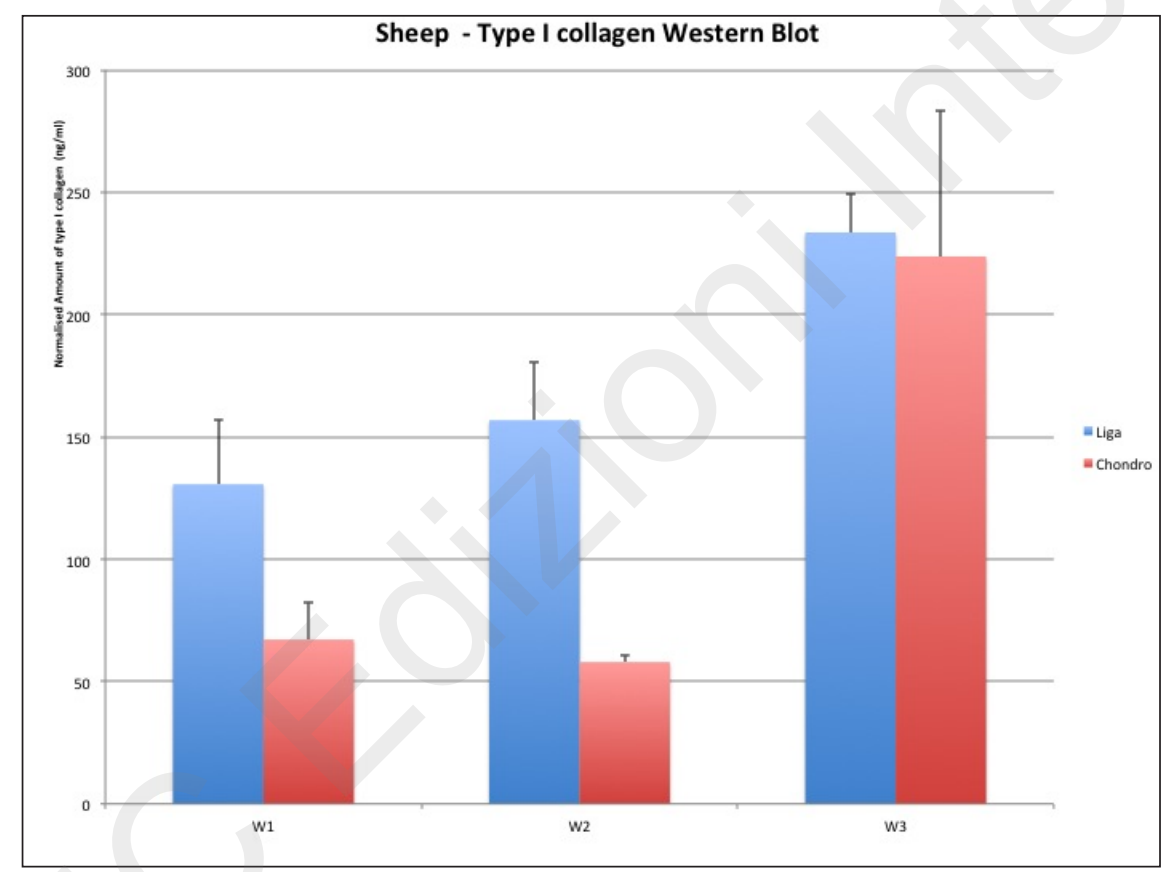

Figure 3. Western blot: type I collagen production over three weeks directly off the graft.

evidence of low quality, and therefore not wholly reliable. All previous studies have found that tendon augmentation grafts have yet to prove themselves in rotator cuff repair?

This study assessed the in vitro biocompatibility of a biphasic collagen sponge with ovine tenocytes. This was determined by assessing DNA production via assay, protein production via Western and Dot blots, and glycoaminoglycans using a DMMB assay. The study hypothesis was that the collagen sponge would be similar in biocompatibility to Ligamimetic. The results show that DNA content on the graft increased over a three-week period, and at a similar rate to the collagen fibre graft. The results also show that the cells not only grow but thrive on the scaffold, with an increasing cell activity indicated by cumulative production of proteins.

A shortcoming of our experiment is the limited number of sheep sampled. More independent samples would have strengthened the data. However, statistical tests performed before the experiment indicated that samples from a minimum of three independent sheep would yield results with adequate power. Our previous experimentation had also shown that this 


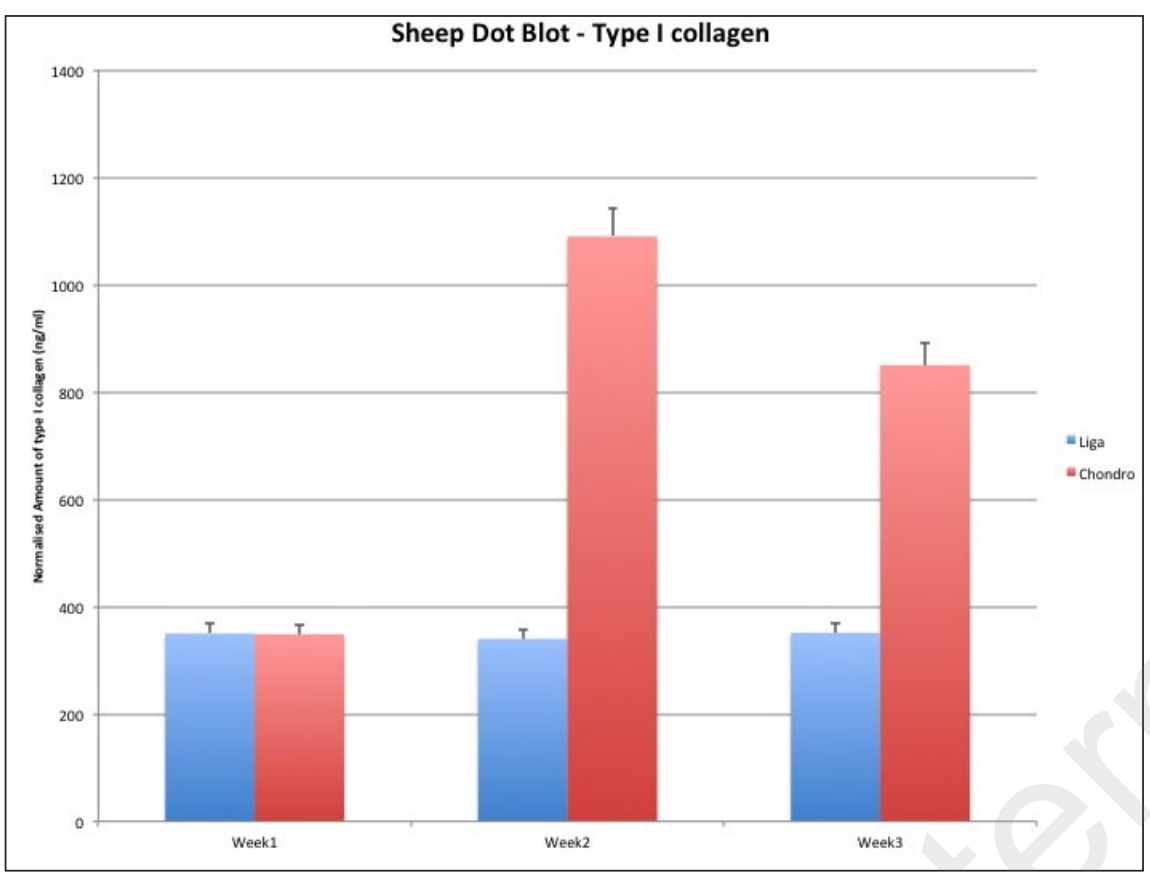

Figure 4. Dot blot: type I collagen measured in the supernatant.

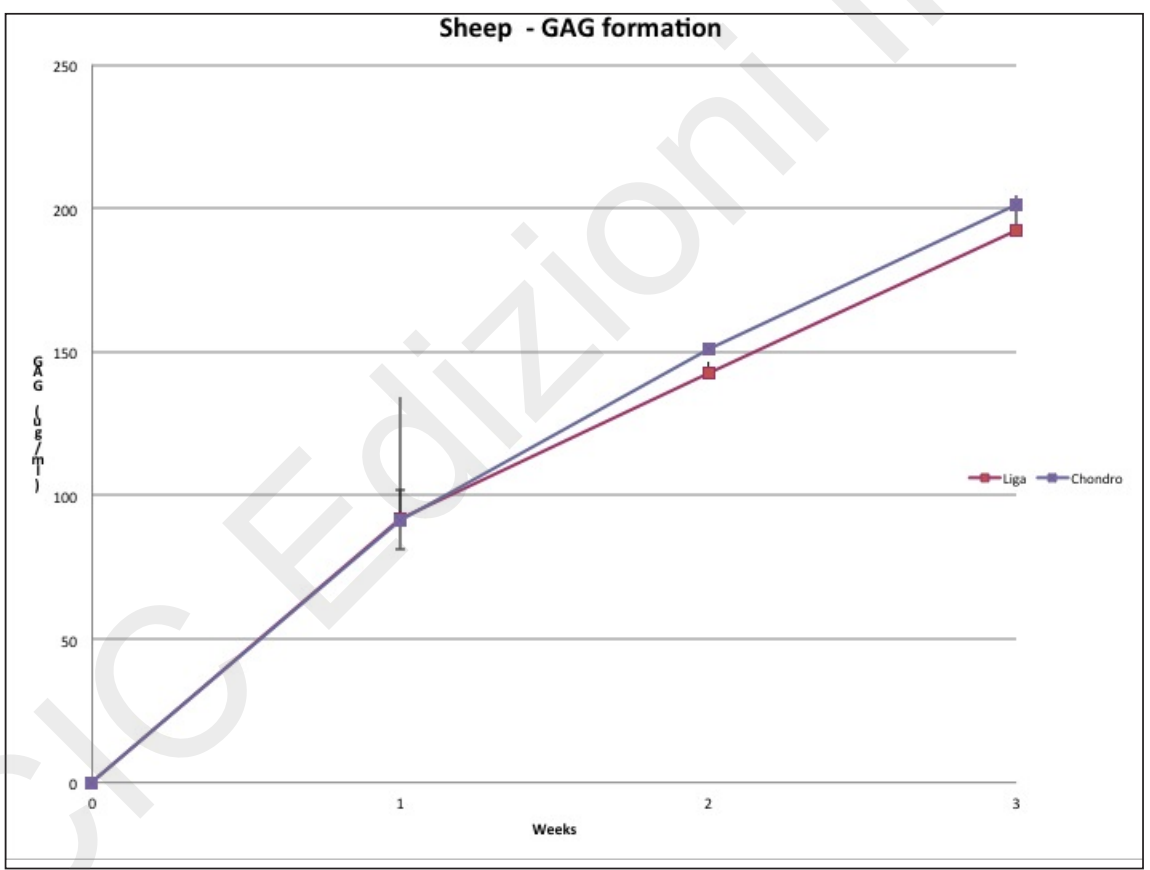

Figure 5. Cumulative GAG formation over three weeks.

would be adequate, nevertheless more samples would have strengthened the data ${ }^{26}$. The other deficit of our experiment was a lack of qualitative information such as microscopy. Although type I collagen and decorin were sampled, more proteins could have been measured, such as tensacin $\mathrm{C}$ and fibronectin.
This may provide further information on whether the type of scaffold influences protein production from tendocytes. Further experimentation may include more detailed in vitro study to address the above discussed limitations, and in vivo study to investigate the effect of collagen sponge graft in a live sheep model. 


\section{Conclusions}

From our experiment we can conclude that the Chondromimetic allows adhesion and proliferation of cells, with increased protein production similar to that on fibre graft. This study is one of the first to find that this biphasic collagen sponge is compatible with ovine rotator cuff tenocytes. The impact of this study is that it will allow further experimentation to be undertaken the in vivo setting in sheep, and ultimately will lead to clinical experimentation of this novel graft.

\section{Acknowledgements}

The Authors gratefully acknowledge the founding support of the Technology Strategy Board (grant number DT/F006977/1) and of the National Institute for Health Research. Dr. Z Ahmad gratefully acknowledges Dr. R Brooks and Dr. J Wardale (University of Cambridge) for their helpfulness and support Dr. Sheraz Malik (Barts Health, London) proof-read the manuscript.

\section{Author contributions}

Z. Ahmad, experiment work, write up.

N. Rushton, experiment work, write up.

\section{Conflicts of interest}

None.

\section{Ethics}

The Authors declare that this research was conducted following basic ethical aspects and international standards as required by the journal and recently update $\mathrm{in}^{27}$.

\section{References}

1. Sharma P, Maffulli N. Biology of tendon injury: healing, modeling and remodeling. J Musculoskeletal Neuronal Interact. 2006;6(2):181-190.

2. Lewis JS. Rotator cuff tendinopathy: a model for the continuum of pathology and related management. $\mathrm{Br} \mathrm{J}$ Sports Med. 2010;44(13):918-923.

3. Oliva F, Piccirilli E, Bossa M, Via AG, Colombo A, Chillemi C, et al. I.S.Mu.L.T - Rotator Cuff Tears Guidelines. MLTJ. 2015;5(4):227-263.

4. Ahmad Z, Howard D, Brooks RA, Wardale J, Henson FM, Get$\operatorname{good} A$, et al. The role of platelet rich plasma in musculoskeletal science. JRSM Short Rep. 2012;3(6):40.

5. Ahmad Z, Brooks R, Kang SN, Weaver H, Nunney I, Tytherleigh-Strong $\mathrm{G}$, et al. The effect of platelet-rich plasma on clinical outcomes in lateral epicondylitis. Arthroscopy. 2013;29 (11):1851-1862.
6. Ahmad Z, Wardale J, Brooks R, Henson F, Noorani A, Rushton $\mathrm{N}$. Exploring the application of stem cells in tendon repair and regeneration. Arthroscopy. 2012;28(7):1018-1029.

7. Ahmad Z, Henson F, Wardale J, Noorani A, TytherleighStrong G, Rushton N. Review article: Regenerative techniques for repair of rotator cuff tears. J Orthop Surg (Hong Kong). 2013;21(2):226-231.

8. Longo UG, Lamberti A, Maffulli N, Denaro V. Tendon augmentation grafts: a systematic review. Br Med B. 2010;94:165188.

9. Kew SJ, Gwynne JH, Enea D, Abu-Rub M, Pandit A, Zeugolis $\mathrm{D}$, et al. Regeneration and repair of tendon and ligament tissue using collagen fibre biomaterials. Acta biomaterialia. 2011;7 (9):3237-3247.

10. Hee CK, Dines JS, Dines DM, Roden CM, Wisner-Lynch LA, Turner AS, et al. Augmentation of a rotator cuff suture repair using rhPDGF-BB and a type I bovine collagen matrix in an ovine model. Am J Sports Med. 2011;39(8):1630-1639.

11. Kato YP, Christiansen DL, Hahn RA, Shieh SJ, Goldstein JD, Silver FH. Mechanical properties of collagen fibres: a comparison of reconstituted and rat tail tendon fibres. Biomaterials. 1989;10(1):38-42.

12. Getgood AM, Kew SJ, Brooks R, Aberman H, Simon T, Lynn AK, et al. Evaluation of early-stage osteochondral defect repair using a biphasic scaffold based on a collagen-glycosaminoglycan biopolymer in a caprine model. Knee. 2012;19(4):422430.

13. Getgood A, Henson F, Skelton C, Herrera E, Brooks R, Fortier LA, et al. The Augmentation of a Collagen/Glycosaminoglycan Biphasic Osteochondral Scaffold with Platelet-Rich Plasma and Concentrated Bone Marrow Aspirate for Osteochondral Defect Repair in Sheep: A Pilot Study. Cartilage. 2012;3 (4):351-363.

14. Getgood A, Henson F, Brooks R, Fortier LA, Rushton N. Platelet-rich plasma activation in combination with biphasic osteochondral scaffolds-conditions for maximal growth factor production. Knee Surg Sports Traumatol Arthrosc. 2011;19 (11):1942-1947.

15. Kew SJ, Gwynne JH, Enea D, Brookes R, Rushton N, Best $\mathrm{SM}$, et al. Synthetic collagen fascicles for the regeneration of tendon tissue. Acta biomaterialia. 2012;8(10):3723-3731.

16. Enea D, Henson F, Kew S, Wardale J, Getgood A, Brooks $\mathrm{R}$, et al. Extruded collagen fibres for tissue engineering applications: effect of crosslinking method on mechanical and biological properties. J Sci Mater Med. 2011;22(6): 15691578.

17. Enea D, Gwynne J, Kew S, Arumugam M, Shepherd J, Brooks $\mathrm{R}$, et al. Collagen fibre implant for tendon and ligament biological augmentation. In vivo study in an ovine model. Knee Surg Sports Traumatol Arthrosc. 2013;21(8):1783-1793.

18. Turner AS. Experiences with sheep as an animal model for shoulder surgery: strengths and shortcomings. J Shoulder Elbow Surg. 2007;16(5 Suppl):S158-163.

19. Zhang G, Ezura Y, Chervoneva I, Robinson PS, Beason DP, Carine ET, et al. Decorin regulates assembly of collagen fibrils and acquisition of biomechanical properties during tendon development. J Cell Biochem. 2006;98(6):1436-1449.

20. Ezura Y, Chakravarti S, Oldberg A, Chervoneva I, Birk DE. Differential expression of lumican and fibromodulin regulate collagen fibrillogenesis in developing mouse tendons. J Cell Biol. 2000;151(4):779-788.

21. Farndale RW, Buttle DJ, Barrett AJ. Improved quantitation and discrimination of sulphated glycosaminoglycans by use of dimethylmethylene blue. Biochim Biophys Acta. 1986;883 (2):173-177.

22. Lädermann A, Denard PJ, Burkhart SS. Management of failed rotator cuff repair: a systematic review. J ISAKOS. 2016; 1(1):32-37. 
23. Ono Y, Davalos Herrera DA, Woodmass JM, Boorman RS, Thornton GM, Lo IK. Graft Augmentation Versus Bridging for Large to Massive Rotator Cuff Tears: A Systematic Review. Arthroscopy. 2017;33(3):673-680.

24. Thangarajah T, Pendegrass CJ, Shahbazi S, Lambert S, Alexander S, Blunn GW. Augmentation of Rotator Cuff Repair With Soft Tissue Scaffolds. Orthop J Sports Med. 2015;3(6): 2325967115587495.

25. Ono Y, Davalos Herrera DA, Woodmass JM, Boorman RS, Thornton GM, Lo IK. Can Grafts Provide Superior Tendon Healing and Clinical Outcomes After Rotator Cuff Repairs? A
Meta-analysis. Orthop J Sports Med. 2016;4(12):2325 967116674191.

26. Howard D, Shepherd JH, Kew SJ, Hernandez P, Ghose S, Wardale JA, Rushton N. Release of growth factors from a reinforced collagen GAG matrix supplemented with platelet rich plasma: Influence on cultured human meniscal cells. J Orthop Res. 2014;32(2):273-278.

27. Padulo J, Oliva F, Frizziero A, Maffulli N. Muscles, Ligaments and Tendons Journal - Basic principles and recommendations in clinical and field science research: 2016 update. MLTJ. 2016;6(1):1-5. 